\title{
Okul Müdürlerinin Yenilik Yönetimi Yeterliklerinin Cinsiyete Göre İncelenmesi: Bir Meta-Analiz Çalışması
}

DOI: 10.26466/opus.739482

$*$

\section{Müzeyyen Petek Dinçman *}

* Dr., Hacettepe Üniversitesi, Yabancı Diller Yüksekokulu, Ankara/Türkiye E-Posta: mpdicman@gmail.com

ORCID: $\underline{0000-0002-3436-6583}$

\section{Öz}

Bu meta-analiz araştırmasının temel amacı Türkiye'de okul müdürlerinin yenilik yönetimi yeterliklerini öğretmenlerin cinsiyetlerine göre inceleyen araştırmaların sonuçlarını meta-analiz yöntemiyle bir araya getirerek detaylı sonuçlar ortaya çıkarmaktır. Ayrıca araştırmada moderatör analiz tekniğiyle cinsiyetin öğretmenlerin okul müdürlerinin yenilik yönetimi yeterliklerine ilişkin algıları üzerindeki etkisi, çalışmaların yıllarına göre (2012-2017 ve 2018-2019) anlaml bir farklllık gösterip göstermediği de incelenmiş̧ir. Araştırmaların etki büyüklükleri için Cohen d olarak da bilinen Standardize Ortalamalar Farkı (SOF) yöntemi kullanılmışıı. Alanyazın taraması sonucunda konu ile ilgili 11 çalışmanın metaanalize alınması uygun görülmüş̧ür. Araştırmanın örneklemini 2406 kadın ve 2046 erkek olmak üzere toplam 4452 öğretmen oluşturmaktadır. Araştırmada sabit etkiler modelinde birleştirme işlemi sonucu kadın öğretmenler lehine .006'llk pozitif ve istatistiksel olarak anlamlı olmayan bir etki büyüklüğü tespit edilmiştir. Bunun yanı sıra moderatör olarak çalışmaların yayın yılı analize alınmıştır. Yayın yılı analizinde de cinsiyetin ortalama etki büyüklü̆̆̈̈̈nün değişmediği saptanmıştır. Araştırmaya göre öğretmen algıları bağlamında okul müdürlerinin yenilik yönetimi yeterliklerinin cinsiyet değişkeni bakımından istatiksel olarak anlamlı bir farklılık göstermediği sonucuna ulaşılmıştır.

Anahtar Kelimeler: $\quad$ Okul müdürleri, Yenilik yönetimi yeterliği, Meta-analiz, Cinsiyet 


\title{
Innovation Management of School Principals Qualifying Examination by Gender: A Meta-Analysis Study
}

\begin{abstract}
The main aim of this meta analysis to prevail detailed consequences of competencies of school principles for innovation management based on gender differencesIn the research, the effect of gender on teachers 'perceptions of school principals' innovation management competencies was examined with the moderator analysis technique, whether the studies showed a significant difference according to their years (2012-2017 and 2018-2019). Standardized Means Difference (SOF) method, also known as Cohen $d$, was used for the effect sizes of the studies. As a result of the literature review, it was deemed appropriate to include 11 studies on the subject in meta-analysis. The sample of the research consists of 4452 teachers, 2406 women and 2046 men. A positive and statistically insignificant effect size of .006 was determined in favor of female teachers as a result of combining in the fixed effects model. The publication year of the studies was analyzed as a moderator. In the publication year analysis, it was found that the average effect size of the gender did not change. It was concluded that the innovation management competencies of school principals in terms of teacher perceptions did't show a statistically significant difference in terms of gender variable.
\end{abstract}

Keywords: School principals, Innovation management competence, Meta-analysis, Gender 


\section{Giriş}

Küresel çapta yaşanan gelişmeler ve değişimler toplumsal yaşamı olduğu kadar farklı sektörlerin örgütsel yaşamlarını da derinden etkilemiştir. Müşteri beklentilerinin ve hizmet anlayışlarının hızla değişmesiyla birlikte örgütlerin varlık sebepleri sorgulanmaya başlanmıştır. Özellikle rekabetçi alanlarda faaliyet gösteren örgütlerde sözü edilen faktörlerin etkileri daha fazla hissedilmiştir (Bülbül, 2013; Demirci, 2013). Örgütler ise varlıklarını sürdürebilmek ve rakip örgütlere karşı hayatta kalabilmek için sürekli çaba sarf etmeye çalışır. Bu nedenle tüm örgütler, amaçlarını gerçekleştirebilmek için kendilerini çevreye adepte etmeyi ve yenilikçi bir örgüt yapısına sahip olmayı arzu eder (Sönmez ve Çekmecelioğlu, 2016; Özevren, 2000). Oysaki belirsizliğe ve rakabete karşı yenilikçi bir örgüt yapısının işlevsel olabilmesi ancak örgütün yenilik yönetimi süreçlerinin sağlıklı işletilebilmesiyle mümkündür. Bu nedenle her örgütün benzer gerekçelerle yenilik yönetimini benimsemek ve önemsemek durumunda olduğu söylenebilir.

Yenilik yönetimi; örgütlerin veya işletmelerin iç ve dış çevrelerde meydana gelen yeniliklere, değişimlere uyum sağlamak üzere yönetsel faaliyetleri harekete geçirmek suretiyle yeniliği kontrol altına alabilmesi ve yönetilebilmesi süreci olarak açıklanmaktadır (Drucker, 2003). Yenilik yönetiminin odağında yeniden yapılanma, değişim ve özgün fikilerin uygulanmasına ilişkin süreçler vardır (European Commission, 2004). Yenilik süreci olarak ifade edilen bu süreçler "yenilikçilik için bir sorunun saptanması, olası fikirlerin oluşturulması, özgün fikirler arasında etkileşimlerin sağlanması, yeniliğin tüm örgüt üyelerince içselleştirilmesi ve yeniliğin somut olarak ürüne dönüştürülmesi" aşamalarını içermektedir (Durna, 2002). Yenilik sürecinin başlayabilmesi için öncelikle yeniliğe ihtiyaç duyulmall, özgün fikirler desteklenmeli, takip edilecek aşamalar belirlenmeli ve yeniliğin örgütün süregelen parçası olana kadar uygulanması sağlanmalıdır (Top, 2011). Çünkü yenilik yönetim süreçleri farklı bir bakış açısı kazandırma, bir alana değer katma ve içinde bulunduğu örgütü besleyen özellikler olması nedeniyle oldukça önemlidir (Hadfield, 2008).

Yenilik yönetimi günümüz bilgi çağına ayak uydurabilmenin kilit nokta-

sını oluşturmaktadır. Örgütlerin yenilik yönetimi stratejilerinin ve poltikalarının olması gerekmektedir. Örgütlerden çevreden ya da dışardan alınan bil- 
giyi kendi içinde yoğurup işleyebilmek için yeniliği yönetilebilme kabiliyetiyle donanımlı olmaları beklenmektedir (Öğüt, Aygen ve Demirel, 2007). Bir yönüyle örgütsel yapılarda yeniliği yönetebilmek ancak belli bir çaba ve dikkatle mümkündür (Bülbül, 2012a). O halde örgütsel yeniliğin tek bir kez gerçekleşmeyip süreklilik gösteren ve belli süreçleri de içine alan eylemler topluluğu olduğu söylenebilir (Ömür, 2014).

Örgütler için yenilik var olan problemlere çözüm üretmenin, dış çevrede ortaya çıan fırsatları iyi değerlendirmenin ve tehditlerden korunmanın aracı olarak görülmektedir. Diğer bir anlatımla örgütte meydana gelen yenilikler, örgütün sürüdürülebilir olmasına ve örgütsel faaliyetlerin devam etmesine katkı sağlar (Uzkurt, 2008). Çünkü yenilik, örgütler açısından ilerlemenin ve farklılaşmanın önemli bir değişkeni olarak görülmektedir (Kuczmarski, 1996). Benzer şekilde Naktiyok (2007) da yeniliği, örgütlerin yeni beceriler kazanmalarında ve değişimi takip etmelerinde yaşanması gereken önemli bir süreç olarak değerlendirmektedir. Ayrıca örgütlerin canlılığını sürdürmesi, farklılık oluşturması ve sürekli gelişim odaklı olması yenilik gerçekleştirebilme kabiliyetleriyle ilgilidir (Rammel, 2003). Yeniliği bir tehlike olarak gören veya görmezden gelen örgütler ise üretkenliklerini kaybederek sürekli bir düşüş eğilimine sürüklenecektir (Adair, 2015). Dolayısıyla yeniliği kabullenen, yeniliğe karşı kendisini güncelleyebilen ve yeniliği bir fırsat olarak alg1layan örgütlerin, başka örgütlere karşı hem rekabet üstünlügü sağlama hem de daha uzun süre varlı̆̆ını devam ettirme konusunda daha avantajlı hale geldikleri anlaşılmaktadır. Bu bağlamda yeniliklerin ve yenilik yönetimi süreçlerinin sağlıklı bir şekilde işletilmesi gereken örgütlerin başında makro düzeyde eğitim örgütleri, mikro düzeyde ise okulların geldiği ifade edilebilir.

Eğitim örgütlerinde yenileşme faaliyetleri toplumsal ve bireysel tavıların değişmesi şekilinde ortaya çıkar. Ancak eğitimde yenileşme sanıldığı gibi basit bir süreç değil olmayıp oldukça karmaşık bir süreçtir. Eğitim ve eğitim örgütleri sözü edilen karmaşık süreçlerden etkilendiği gibi aynı zamanda bu karmaşık süreçlere de etki eder (Varış, 1982). Aslında eğitimde yenilik; nitelikli bir eğitim sağlamak, özgün düşünebilen bireyler yetiştirmek, okulu etkili hale getirmek ve öğrencilere günün ihtiyaçlarına cevap verebilecek beceriler kazandırmaktır. Okullar ise risk almaktan korkmayan, kendini geliştirmek isteyenlere çeşitli ortamlar ve firsatlar sağlayan özellikleriyle yenilikçi olabilirler (Musluoğlu, 2008 akt. Göl ve Bülbül, 2012; Watt, 2002). Bu nedenle çoğu 
kez okullar, yeniliği işe koşacak yapılara gereksinim duyar ve yenilik yönetimiyle ilgili becerilerin gelişmesi için çaba sarf eder. Bursalıoğlu'na (2012) göre okullar, sosyal yaşamın yenilenmesinde ve değişmesinde çok önemli görevler üstlenir. Okullar, bireyi yetiştirme sorumluluklarını yerine getirmekle sanat, ekonomi, siyaset gibi daha birçok kurumunun değişmesinde ve gelişmesinde büyük bir rol oynar. Pervaiz (1998) okulların bir örgüt olarak yeniliği ve yenilik yönetimi süreçlerini kendileri açısından bir strateji olarak görüp uygulamalarında okulun kültürel yapısına vurgu yapar ve bu süreçte öğrenci, öğretmen, veli desteğinin yanı sıra en büyük sorumluluğun okul müdürlerinde olduğunu belirtmektedir. Tam da bu noktada okul müdürlerinin, okullarda yenilik yönetiminin hayata geçirilmesinde belirleyici bir rol üstlendikleri iddia edilebilir.

Eğitim örgütlerinin ve okulların toplumun beklentilerini karşılayabilecek düzeye ulaşması okul müdürlerinin yönetim yaklaşımı ve becerisiyle doğrudan ilişkilidir. Lider olarak okul müdürleri, görev yaptıkları okullarda değişimi ve yeniliği herkesten önce öngörebilmelidir (Günbayı, 2016). Yenilikçi okul müdürleri, diğer müdürlerden farklı olarak vizyon, destek ve güven odaklı liderlik davranışları sergiler (Watt, 2002). Beycioğlu ve Aslan (2009) yenilik yönetimi çerçevesinde okul müdürlerinden yerine getirmeleri beklenen liderlik davranışlarını "yeniliği gerekli görüp okula yansıtma, her türlü teknolojik değişimi okula sunma, öğrenmede öncü olma ve öğrendiklerini başkalarıyla paylaşma" şeklinde sıralamaktadır. Adiar (2007) yenilikçi okul müdürlerini okulların temel yapı taşı olarak yeniliğin yayılmasına ivme kazandıran, bütüncül düşünen, iyi iletişim kurabilen, yenilikçi kültürün yerleşmesine imkân sağlayan ve derin düşünme yeteneklerine sahip olan kişiler olarak tanımlamaktadır. Fullan (2007) ise yenilikçi okul müdürlerinin ilişki odaklı, dişa dönük ve yeni fikirlere açı olabilme yeterliklerine dikkat çekmektedir. Bu çerçevede her okul müdürünün yaşanan değişimi ve yeniliği okullarına sağlıklı bir şekilde yansıtabilmek için bazı yeterliklerle donanımlı olması gerektiği ve okul müdürlerinin yenilik yönetimi yeterliklerinin okullarda yenilik yönetimi sürecinin başlamasında ve süreklilik göstermesinde belirleyici bir faktör olduğu anlaşılmaktadır.

Ulusal ve uluslararası alanyazını incelendiğinde son yıllarda okullarda yenilik yönetimi konusuyla ilgili araştırmaların sayısında ciddi bir artış olduğu görülmektedir (Ağaoğlu, Altınkurt, Yılmaz ve Karaköse, 2012; Akomo- 
lafe, 2011; Argon, İsmetoğlu ve İşeri, 2014; Aydoğar, 2018; Bayrakçı ve Eraslan, 2014; Boydak Ozan ve Karabatak, 2013; Bülbül, 2012b; Damanpour ve Schneider, 2006; Demiraçan, 2019; Dönmez, 2018; Göl, 2012; Greany, 2018; Eraslan, 2014; Eroğlu Bozkurt, 2019; Esen, 2016; Göl ve Bülbül, 2012; Görgel, 2018; Jolles, McBeath, Carnochan ve Austin, 2016; Judd, 2017; Karaca, 2019; Top, 2011; Karataş, Gök ve Özçetin, 2015; Koch, Binnewies ve Dormann, 2015; Kurt, 2016; Min, Ling ve Piew, 2016; Mürtezaoğlu, 2015; Orapeleng, 2017; Ömür, 2014; Öztürk, 2017; Park, 2012; Pihie, Asimiran ve Bagheri, 2014; Selçuk, 2018; Şahin, 2018; Watt, 2002; Yaman, 2018). Bu araştırmaların ulusal düzeyde yapılanlardan bir kısmı ise öğretmen algıları doğrultusunda çeşitli kişisel (demografik) değişkenlere göre okul müdürlerinin yenilik yönetimi yeterliklerini saptamaya yöneliktir (Aydoğar, 2018; Eraslan, 2014; Eroğlu Bozkurt, 2019; Dönmez, 2018; Göl, 2012; Görgel, 2018; Kurt, 2016; Ömür, 2014; Öztürk, 2017; Selçuk, 2018; Şahin, 2018). Ancak söz konusu araştırmaların bazılarında öğretmenlerin cinsiyetleri ile okul müdürlerinin yenilik yeterliklerine ilişkin algılar arasında anlamlı bir ilişki varken (Argon ve Özçelik, 2007; Bayrakçı ve Eraslan, 2014; Erslan, 2014), bazılarında ise anlamlı bir ilişkinin olmadığı belirlenmiştir (Aydoğar, 2018; Dönmez, 2018; Eroğlu Bozkurt, 2019; Göl, 2012; Görgel, 2018; Kurt, 2016; Ömür, 2014; Öztürk, 2017; Selçuk, 2018; Şahin, 2018).

Anlaşılacağı üzere ulusal alanyazınında öğretmen algılarına göre okul müdürlerinin yenilik yönetimi yeterliklerinin incelendiği araştırmalarda cinsiyet değişkeni bakımından farklı sonuçların olduğu görülmektedir. Bu nedenle okul müdürlerinin yenilik yönetimi yeterliklerinin öğretmenlerin cinsiyetlerine göre meta-analiz yöntemiyle incelenerek sentezlenmesi daha net ve daha doğru sonuçlara ulaşmaya katkı sunabilir. Ayrıca okul müdürlerinin yönetim yeterliklerinin öğretmenlerin cinsiyetleri bakımından ele alan bir meta-analiz çalışmasına rastlanmaması da böyle bir araştırmanın yapılmasını gerekli kılmıştır. Araştırmanın okul müdürlerinin yenilik yönetimi yeterliklerinin öğretmenlerin cinsiyetlerine bağlı olarak değişip değişmediğini göstermesi yönünden kayda değer katkı sağlayacağı düşünülmektedir. Ayrıca araştırmanın meta-analiz yöntemiyle yapılmasının uygulayıcılara ve politika yapıcılara okul müdürlerinin yenilik yönetimi yeterliklerinin saptanmasında çoklu bir bakış açısı kazandıracağı tahmin edilmektedir. 


\section{Araştırmanın Amacı}

Araştırmanın temel amacı Türkiye' de okul müdürlerinin yenilik yönetimi yeterliklerini öğretmenlerin cinsiyetlerine göre inceleyen araştırmaların sonuçlarını meta-analiz yöntemiyle bir araya getirerek detaylı sonuçlar ortaya çıkarmaktır. Bu bağlamda araştırmada aşağıdaki sorulara cevap aranmaya çalişılmıştır;

1. Cinsiyet değişkeni, öğretmenlerin okul müdürlerinin yenilik yönetimi yeterliklerine ilşkin algıları üzerinde hangi düzeyde bir etki büyüklüğüne sahiptir?

2. Cinsiyetin öğretmenlerin okul müdürlerinin yenilik yönetimi yeterliklerine ilişkin algıları üzerindeki etkisi, çalışmaların yıllarına göre (20122017 ve 2018-2019) anlamlı bir farklılık göstermekte midir?

\section{Yöntem}

\section{Araştırmanın Modeli}

Araştırma, alanyazın tarama yöntemlerinden biri olarak kabul edilen metaanaliz yöntemiyle yapılmıştır. Meta-analiz; herhangi bir konu hakkında yapılmış tüm araştırmaların nicel bulgularının belli ölçütler dahilinde istatiksel olarak bir araya getirilerek belli bir sonuca ulaşılmasıdır (Borenstein, Hedges, Higgins ve Rothstein, 2013; Dinçer, 2014). Meta analiz, araştırmalara özgü bazı sınırlıkları ortadan kaldırır ve bağımsız araştırmalardan elde edilen verilerden objektif sonuçlar elde edilmesine imkân sağlar (Cooper, Hedges ve Valentine, 2009).

\section{Alanyazın Taraması ve Veri Toplama Süreci}

Araştırma kapsamında okul müdürlerinin yenilik yönetimi yeterliklerini öğretmenlerin cinsiyetlerine göre ele alan araştırmalar incelenmiştir. Araştırmaya girecek çalışmaları belirlemek üzere "Yükseköğretim Kurulu Ulusal Tez Merkezi, ULAKBİM Ulusal Veri Tabanı, Google Akademi, EBSCOhost, Science Direct, ASOS, Scopus" gibi akademik veri tabanlarından yararlanılmıştır. Akademik veri tabanlarındaki taramalar 1 Mayıs 2020-10 Mayıs 2020 tarihleri arasında "yenilik, yenilik, yönetimi, yenilik yönetimi yeterlikleri, inovasyon, cinsiyet, innovation, innovation management, innovation mana- 
gement competencies, sex, gender" kelimeleriyle ve veri tabanlarındaki gelişmiş arama özellikleriyle gerçekleştirilmiştir. Bu tarmalar sonucunda eğitim örgütlerinde yapılmış olan 85 araştırmaya ulaşılmıştır. Araştırmaya dâhil olacak çalışmalar şu ölçütlere göre belirlenmiştir;

- Çalışmaların erişime açık yüksek lisans tezi, doktora tezi veya hakemli dergilerde yayımlanmış makale olması,

- Çalışamların geçerli ve güvenilir bir ölçme aracıyla yapılmış olması,

- Çalışmaların nicel araştırmalar olması,

- Çalışmalarda cinsiyet değişkeninin olması,

- Çalışamalara katılan kadın ve erkek sayısının belli olması,

- Kadın ve erkek katılımcılara ilişkin aritmetik ortalama, standart sapma, $\mathrm{t}$ veya p değerlerinin verilmiş olması,

- Çalışmaların eğitim örgütlerinde görev yapan okul müdürlerinin yenilik yönetimi yeteliklerini inceliyor olması,

- Çalışmaların öğretmen algılarına göre gerçekleştirilmiş olması,

- Çalışmların 01.01.2010 - 31.12.2019 tarihleri arasında yapılmış olması şartı göz önünde bulundurulmuştur.

Yukarda belirtilen ölçütlere göre toplam 11 çalışmanın meta-analize dâhil edilmesi uygun görülmüştür. Araştırmaya dâhil olan çalışmalar ise kaynakçada $\left(^{*}\right)$ işaretiyle belirtilmiştir. Araştırmaya 11 çalışmaya nasıl ulaşıldığını gösteren akış şeması ise Şekil 1'de verilmiştir.

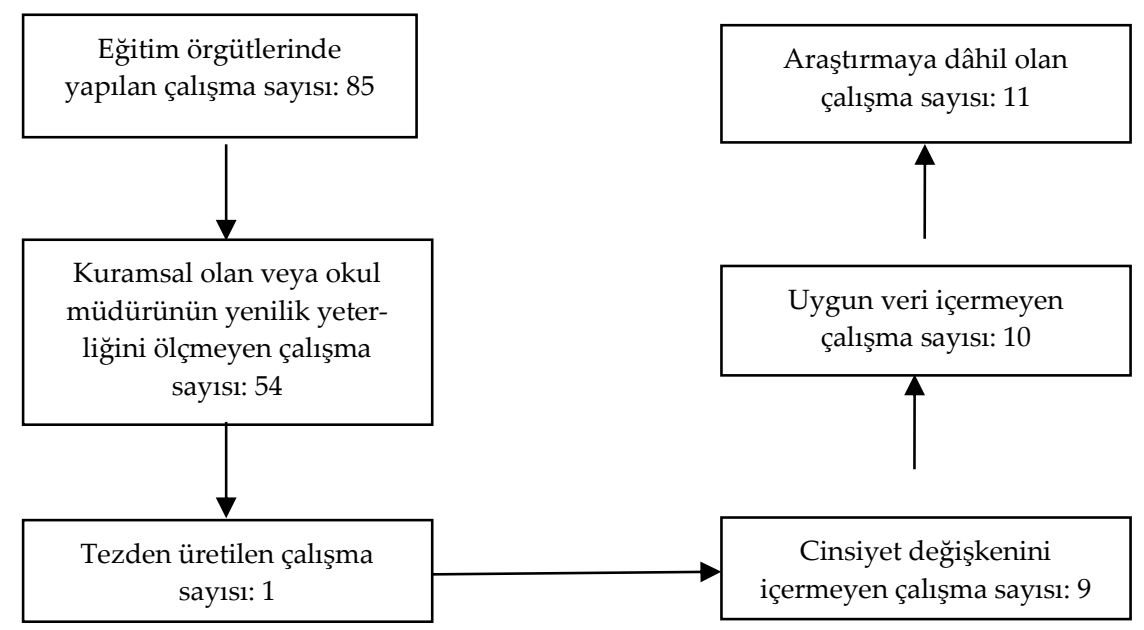

Şekil 1. Araştırmaya dâhil olan çalışmalara ilişkin akış şeması 
Tablo 1'de meta-analize dâhil olan toplam 11 çalışmaya ilişkin betimsel bilgiler görülmektedir.

Tablo 1. Meta-analize dâhil olan çalışmalarn betimsel istatistikleri

\begin{tabular}{llll}
\hline Değişkenler & Değişken Bilgisi & f & \% \\
\hline Çalışmaların Türü & Yüksek Lisans & 11 & 100 \\
\hline \multirow{4}{*}{ Çalışmaların Yılı } & 2012 & 1 & 9 \\
& 2014 & 2 & 18 \\
& 2016 & 1 & 9 \\
& 2017 & 1 & 9 \\
& 2018 & 5 & 46 \\
& 2019 & 1 & 9 \\
\hline \multirow{4}{*}{ Çalışmaların Uygulandığı Okul Kademesi } & İkokul & 1 & 9 \\
& İköğretim & 1 & 9 \\
& Ortaokul & 2 & 18 \\
& Lise & 5 & 46 \\
& Hepsi & 2 & 18 \\
\hline \multirow{4}{*}{ Çalışmaların Yapıldığı İller } & Kahramanmaraş & 2 & 18 \\
& Muğla & 1 & 9 \\
& Çanakkkale & 1 & 9 \\
& Bolu & 2 & 18 \\
& Zonguldak & 1 & 9 \\
& Ankara & 1 & 9 \\
\hline \multirow{2}{*}{ Cinsiyet } & Kırklareli & 1 & 9 \\
& İstanbul & 2 & 18 \\
\hline
\end{tabular}

Tablo 1'de görüldügü gibi meta-analize dâhil olan tüm araştırmalar yüksek lisans tezi türündedir ve öğretmen algılarına göre okul müdürlerinin yenilik yönetimi yeterlikleri konusunda en çok 2018 yılında çalışma yapılmıştır ( $\mathrm{f}=5 ; \% 46)$. Araştırmaların daha çok liselerde $(\mathrm{f}=5 ; \% 46)$; iller bazında ise Kahramanmaraş ( $\mathrm{f}=2 ; \% 18)$, Bolu ( $\mathrm{f}=2 ; \% 18)$, ve İstanbul'da ( $\mathrm{f}=2 ; \% 18)$ yapıldığ görülmektedir. Araştırmanın katılımcıları 2406'sı (\%55) kadın, 2046's1 (\%45) erkek toplam 4452 öğretmen oluşmaktadır.

\section{Araştırmanın Kodlama Sürecinin Geçerlik ve Güvenirliği}

Araştırmaya dâhil olan tüm çalışmaların geçerlik ve güvenirlikleri tek tek kontrol edilmiştir. Araştırmanın kodlama süreci geniş ve ayrıntılı bir şekilde gerçekleştirilmiştir. Bu doğrultuda araştırma kapsamında kodlanan veriler bir başka bağımsız araştırmacı tarafından yeniden kodlanmıştır. İki kodlayıcı 
arasındaki uyum için Cohen Kappa katsayısı hesaplanmıştır. Cohen Kappa katsayısının $\kappa=.94$ olduğu saptanmıştır. Ayrıca geri kalan kodlamalar arasındaki tutarsızlıklar da yeniden incelenmiş ve kodlayıcılar arasında tam bir görüş birliği sağlanmıştır.

\section{Verilerin Çözümlenmesi}

Araştırmaya ilişkin analizler Comprehensive Meta-Analysis 2.00 (CMA 2.00) paket programıla gerçekleştirilmiştir. Araştırmaların etki büyüklükleri için Cohen $d$ olarak da bilinen Standardize Ortalamalar Farkı (SOF) yöntemi kullanılmıştır. 00 - .10 arası değer çok zayıf etki büyüklüğü, .10 - .30 arası değer zayıf düzey etki büyüklüğü, $.30-.50$ arası değer orta düzey etki büyüklüğü, $.50-.80$ arası değer güçlü düzey etki büyüklüğü ve $.80^{\prime}$ den büyük değerler ise çok güçlü düzeyde etki büyüklüğü olarak değerlendirilmektedir (Cohen, Manion ve Morrison, 2007). Bu çerçevede her araştırmanın örneklem büyüklüğü (kadın ve erkek) ve aitmetik ortalama, standart sapma, $t$ ve $p$ değerleri incelenmiştir. Araştırmada kadınlar $=1$, erkekler $=0$ olarak kodlanmıştır. Araştırmada pozitif etki büyüklüğü kadınların, negatif etki büyüklügü̈ ise erkeklerin yenilik yönetimi yeterliğine ilişkin algılarının daha olumlu olduğu anlamina gelmektedir.

Meta-analizde etki büyüklükleri sabit etkiler modeli ve rastgele etkiler modeline göre yapılmakla birlikte özelllikle sosyal bilimler alanında daha çok rastgele etkiler modeli önerilmektedir (Cumming, 2012). Bu araştırmada ise hangi modelin kullanılacağına karar vermek için homojenlik testi sonuçlarına bakılmıştır. Homojenlik testi için $Q$ ve $p$ değerleri ölçüt alınmıştır. $Q$ değerinin $x^{2}$ tablosundaki $Q$ değerinden küçük, $p$ değerinin ise .05 'ten büyük olması araştırmanın homejenliğine; $Q$ değerinin $x^{2}$ tablosundaki $Q$ değerinden büyük, $p$ değerinin .05 'ten küçük olması ise araştırmanın heterojenliğine işaret etmektedir (Cooper, Hedges ve Valentine, 2009; Higgins, Thomson, Deeks ve Altman, 2003). Ayrıca araştırmada cinsiyet ile yenilik yönetimi yeterliği algısı arasındaki ilişkide çalışmaların yılları moderatör değişken (2012-2017 ve 2018-2019) olarak tanımlanmıştır. Araştırmanın yayın yanlılığını berlirlemek için “Huni Grafiği (Funnel Plot), Egger testi, Begg ve Mazumdar sıra korelasyonu" değerleri incelenmiştir. Araştırmada istatistiksel anlamlılık $p=.05$ düzeyinde yorumlanmıştır. 


\section{Bulgular}

\section{Yayın Yanlılı̆̆ına (Publication Bias) İlişkin Bulgular}

Yayın yanlılığı, meta-analize sadece anlamlı ve yayınlanmış araştırmalara yer verilmesi, istatiksel olarak anlamlı olmayan ve yayınlanmamış araştırmaların ise dâhil edilmemesi sonucunda ortaya durumu ifade eder (Rothstein, Sutton ve Borenstein, 2005). Meta-analiz çalışmalarında yayın yanlılı̆̆ını belirlemek için Huni Grafiği (Funnel Plot), Egger testi, Begg ve Mazumdar sıra korelasyonu gibi farklı testler kullanılmaktadır (Dinçer, 2014; Duval ve Tweedie, 2000). Araştırmanın yayın yanlılığı da Huni Grafiği (Funnel Plot), Egger testi, Begg ve Mazumdar sıra korelasyonu testi değerleri incelenerek saptanmıştır. Bu bağlamda Grafik 1'de araştırmaya dâhil olan toplam 11 çalışmanın huni saçlım (funnel plot) grafiği görülmektedir.

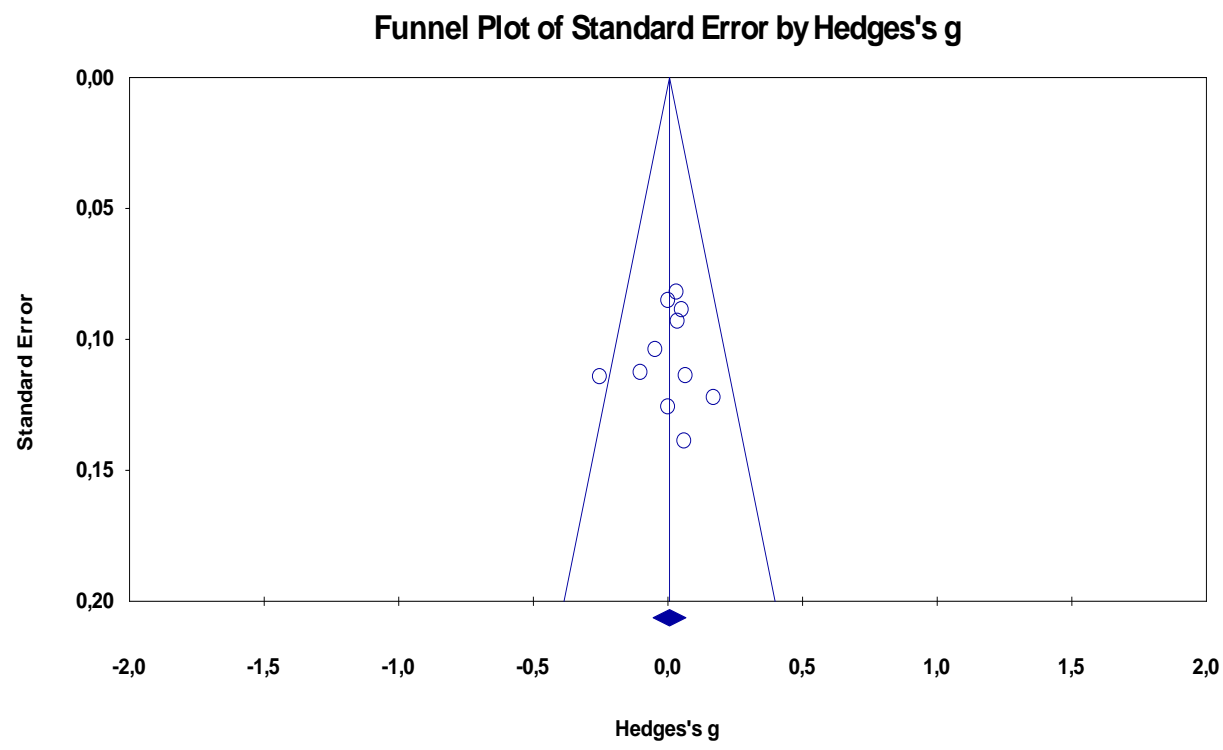

Grafik 1. Araştırmanın yayın yanlılı̆̆ıa iliş̧kin huni saçılım grafiği 
Meta-analiz araştırmalarında çalışmaların etki büyüklüklerinin dikey çizginin her iki tarafına eşit bir dağılım göstermesi yayın yanlılığının olmadığ anlamına gelmektedir (Borenstein vd., 2013). Grafik 1'de görüldüğü gibi araştırmadaki 11 çalışmanın etki büyüklüğü, dikey çizginin her iki tarafına simetrik ve eşit bir biçimde dağılmaktadır. Bu nedenle huni saçılım grafiği, araştırmanın yayın yanlılığının olmadığına işaret etmektedir. Ancak yayın yanlılığına karar verebilmek için Egger testi ile Begg ve Mazumdar sıra korelasyonu testi sonuçlarına da bakılmıştır. Tablo 2'de araştırmanın yayın yanlılığına ilişkin Egger testi ile Begg ve Mazumdar sıra korelasyonu testi sonuçları görülmektedir.

Tablo 2. Egger testi ile Begg ve Mazumdar sıra korelasyonu testi sonuçlar

\begin{tabular}{llll}
\hline Egger Testi & & \multicolumn{2}{l}{ Begg ve Mazumdar Sıra Korelasyonu Testi } \\
\hline $\mathrm{t}$ değeri & $=.26$ & Tau değeri & $=-.01818$ \\
df değeri & $=9$ & Z değeri & $=.07785$ \\
$p$ değeri (çift kuyruklu) & $=.79$ & $p$ değeri (çift kuyruklu) & $=.93$ \\
\hline
\end{tabular}

Tablo 2'den anlaşılacağı üzere Egger testi sonucunda $p$ değerinin .79 ve .05 ten büyük olması, Begg ve Mazumdar Sira Korelasyonu testinde de Tau değerinin $0.1818, Z$ değerinin .07785 ve $p>.05$ ( $p=.93$ ) olmas1 (Card, 2012) bu araştırmada yayın yanlılığının olmadığını doğrulamaktadır.

\section{Heterojenlik Testi Bulgularn}

Araştırmada sabit etkiler modelinin mi yoksa rastele etkiler modelinin kullanılıp kullanılmayacağına karar vermek için heterojenlik testi hesaplanmıştır. Heterojenlik testi sonucunda $Q=8.951, \mathrm{df}=10, p=.537$ olduğu saptanmıştır. Buna göre $p$ değerinin $.05^{\prime}$ ten büyük ve $Q$ değerinin $x^{2}$ tablosounda df değeri 18.307 'ten küçük olması nedeniyle araştırmanın homojen yapıda olduğu anlaşılmıştır. Böylece sabit etkiler modeline göre hesaplanan etki büyüklüğü dikkate alınmıştır. Tablo 3'te araştırmanın heterojenlik testi bulguları yer almaktadır.

Tablo 3. Araştırmanın hetrojenlik testi bulguları

\begin{tabular}{llll}
\hline Heterojenlik değeri $(Q)$ & df & Ki-kare $x^{2}$ tablo değeri & $p$ \\
\hline 8.951 & 10 & 18.307 & .537 \\
\hline
\end{tabular}


Meta-analize dâhil olan araştırmaların homojen olduğunu doğrulamak için huni grafiği incelenmiştir. Grafik 2 'de de görüldüğü gibi heterojenlik testi huni grafiğine göre araştırmadaki 11 çalışmanın

hemen hemen hepsinin eğim çizgileri içerisinde olduğu tespit edilmiştir. $\mathrm{Bu}$ da araştırmanın homojen olduğunun bir başak göstergesi olarak yorumlanabilir.

\section{Funnel Plot of Precision by Hedges's $g$}

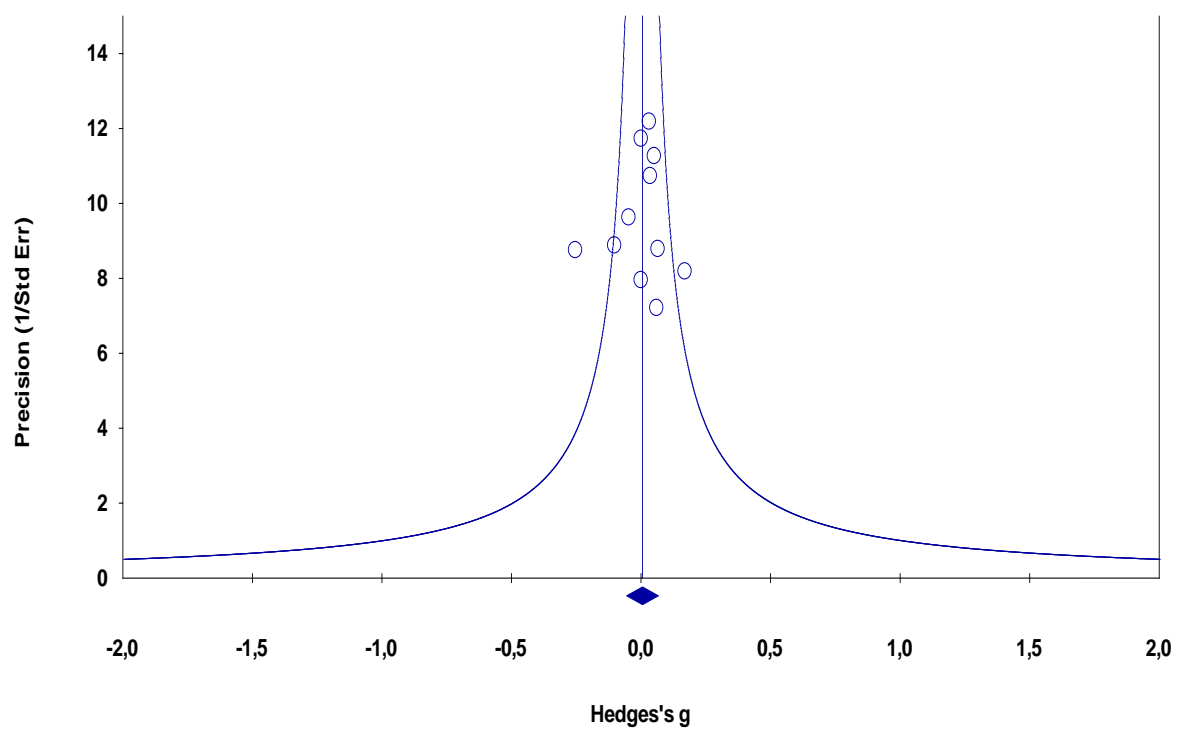

Grafik 2. Araştırmanın heterojenliğine ilişkin huni grafiği

\section{Cinsiyete Göre Etki Büyüklüklerine İlişkin Bulgular}

Cinsiyetin yenilik yönetimi yeterlikleri algısı üzerindeki etkisini inceleyen 11 araştırmaya ait etki büyüklüklerinin sabit etki modellerine göre etki büyüklüğü, \%95 güven aralığında alt ve üst sınırları ile $\mathrm{z}$ ve $\mathrm{p}$ değerleri Tablo 4 'te sunulmuştur. 
Tablo 4. Sabit etki modeline göre çalışmalarn etki büyüklükleri, alt ve üst değerleri, $z$ ve p değerleri

\begin{tabular}{|c|c|c|c|c|c|c|}
\hline \multirow{2}{*}{ Araştırmanın Adı } & \multirow{2}{*}{ Etki Büyüklüğü } & \multicolumn{2}{|c|}{ Güven Aralığı (CI: \%95) } & \multirow[t]{2}{*}{$Z$} & \multirow[t]{2}{*}{$p$} & \multirow[t]{2}{*}{$\mathbf{N}$} \\
\hline & & Alt Sinir & Üst Sınır & & & \\
\hline Göl, 2012 & -.044 & -.248 & .160 & -.426 & .670 & 396 \\
\hline Eraslan, 2014 & -.250 & -.475 & -.026 & -2.185 & .029 & 309 \\
\hline Ömür, 2014 & .172 & -.068 & .412 & 1.406 & .160 & 272 \\
\hline Kurt, 2016 & .054 & -.121 & .228 & .604 & .546 & 528 \\
\hline Öztürk, 2017 & -.099 & -.321 & .122 & -.880 & .379 & 398 \\
\hline Selçuk, 2018 & .063 & -.209 & .336 & .454 & .650 & 226 \\
\hline Aydoğar, 2018 & .038 & -.145 & .221 & .410 & .682 & 476 \\
\hline Görgel, 2018 & .003 & -.164 & .171 & .038 & .970 & 548 \\
\hline Dönmez, 2018 & .068 & -.155 & .292 & .598 & .550 & 414 \\
\hline Şahin, 2018 & .003 & -.244 & .250 & .025 & .980 & 255 \\
\hline Eroğlu Bozkurt, 2019 & .034 & -.127 & .196 & .419 & .675 & 630 \\
\hline Sabit Etki & .006 & -.055 & .037 & .185 & .853 & 4452 \\
\hline
\end{tabular}

Tablo 4'e göre meta-analize alınan 11 araştırmanın cinsiyete göre standardize edilmiş etki büyüklükleri -.250 erkekler lehine değer ile .172 kadınlar lehine değer arasında değişmektedir. Cinsiyetin yenilik yönetimi algısı üzerindeki etkisini inceleyen 11 araştırmanın tamamı için sabit etkiler modeline göre etki büyüklüğü .006 değerle kadınların lehine bulgulanmıştır. Ancak bu etkinin de istatiksel olarak anlamlı olmadığı görülmektedir. Dolayısıyla cinsiyetin yenilik yönetimi algısı üzerinde bir etkiye sahip olmadığı söylenebilir. Meta-analize dâhil olan 11 araştırmanın etki büyüklerine ilişkin orman grafiği (forest plot) ise Grafik 3'te verilmiştir. 


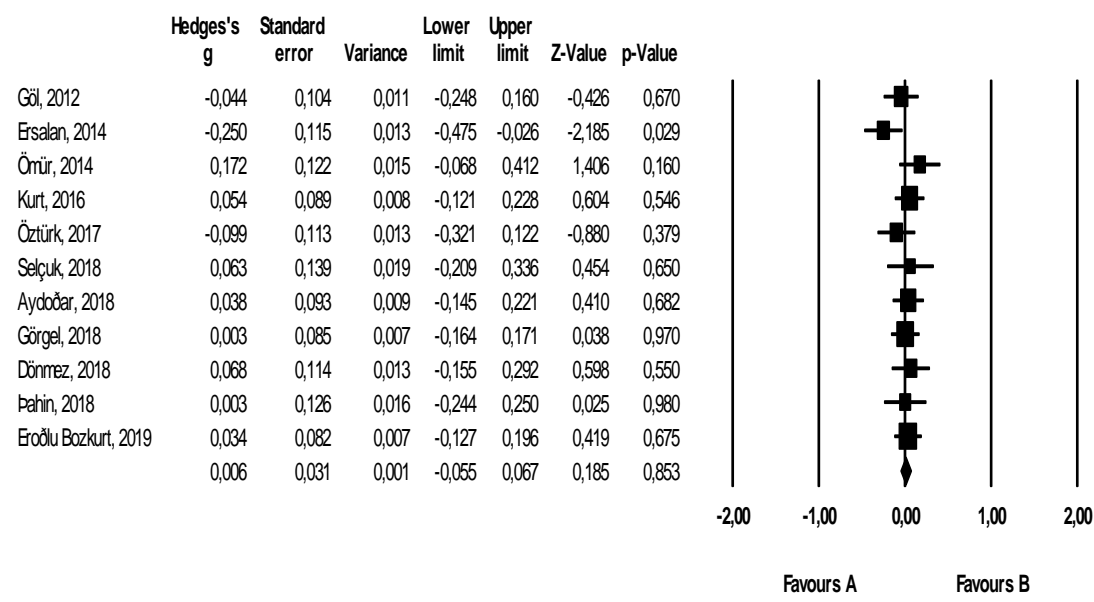

Meta Analysis

Grafik 3. Araştırmaya ait orman grafiği (forest plot)

Grafik 2'de cinsiyetin yenlik yönetimi algısı üzerindeki etkisini inceleyen 11 araştımaya ait Cohen's $d$ etki büyüklükleri yer almaktadır. Her bir araştırmanın etki büyüklüğü kareler şekilinde, en sonda bulunan elmas şekli ise tüm araştırmalara ait genel etki büyüklüğünü ve genel etki büyüklügünün güven aralığını temsil etmektedir. Karelerin iki yanında uzanan çizgiler de \% 95 güven aralığını ifade etmektedir (Dinçer, 2014; Üstün ve Eryılmaz; 2014). Dolayısıyla Grafik 2, toplam etki büyüklüğüne ilişkin alt ve üst güven aralıklarının -.475 ile .412 değerler arasında değişim gösterdiğini doğrular niteliktedir.

Cinsiyetin Yenilik Yönetimi Algısı Üzerindeki Ortak Etki Büyïklüğünün “Çalışmaların Yillarına Göre (2012-2017 ve 2018-2019)" Moderatör Analiz Bulgular

Araştırmada cinsiyetin yenilik yönetimi algısı üzerindeki ortak etki büyüklügünün "çalışmaların yıllarına göre (2012-2017 ve 2018-2019) moderatör analiz bulguları incelenmiş ve elde edilen sonuçlar Tablo 5'te verilmiştir. 
Tablo 5. Araştırmanın yıllara göre (2012-2017 ve 2018-2019) ve sabit etkiler modeli bakımindan moderatör analiz bulgularn

\begin{tabular}{llllllll}
\hline Moderatör & $\mathbf{k}$ & $\boldsymbol{d}$ & $\mathbf{S E}$ & $\mathbf{9 5} \% \mathbf{C I}$ & $\mathbf{Q}_{\mathrm{b}}$ & $\boldsymbol{P}$ & $\boldsymbol{I}^{\mathbf{2}}$ \\
\hline Çalısma Yılı & & & & & & & \\
2012-2017 yılları arası & 5 & -0.029 & 0.048 & $-0.123-0.065$ & 8.889 & 0.543 & 0.000 \\
2018-2019 yılları arası & 6 & 0.030 & 0.041 & $-0.051-0.111$ & & & \\
\hline
\end{tabular}

$\mathrm{k}=$ Çalışma sayısı; $\mathrm{Q}_{\mathrm{b}}=$ Gruplararası $\mathrm{Q}$ değeri

Tablo 5'te görüldüğü gibi çalışmaların yayın yılına göre cinsiyet açısından etki büyüklüğü 2012-2017 yılları arası için -0.029; 218-2019 yılların için 0.030 olarak hesaplanmıştır. Çalışma yılı moderatörü bakımından çalışmalar arası varyans değeri istatistiksel olarak anlamlı olmadığı bulgulanmıştır $\left(\mathrm{Q}_{b}=8.889\right.$ , $p>$.05). Buna göre çalışma yılının cinsiyet açısından etki büyüklüğünü anlamlı bir şekilde değiştirmediği saptanmıştır.

\section{Tartışma, Sonuç ve Öneriler}

Bu meta-analiz çalışmasının temel amacı Türkiye'de okul müdürlerinin yenilik yönetimi yeterliklerini öğretmenlerin cinsiyetlerine göre inceleyen araştırmaların sonuçlarını meta-analiz yöntemiyle bir araya getirerek detaylı sonuçlar ortaya çıarmaktır. Araştırmaya yurt içinde yapılan ve belirlenen ölçütlere uygun toplam 11 çalışma dâhil edilmiştir. Dâhil edilen çalışmaların katılımciları 2406'sı kadın, 2046's erkek olmak üzere 4452 öğretmenden oluşmaktadir.

Araştırmada hangi modelin kullanılacağına karar vermek için homojenlik testi sonuçlarına bakılmıştır. Homojenlik testi sonucunda $p$ (.537) değerinin.05'ten büyük ve $Q$ (8.951) değerinin $x^{2}$ tablosounda df değeri 18.307 'ten küçük olması nedeniyle araştırmanın homojen yapıda olduğu anlaşılmıştır. Böylece sabit etkiler modeline göre hesaplanan etki büyüklüğü dikkate alınmıştır. Sabit etkiler modelinde yapılan birleştirmeler sonucunda kadınlar lehine .006 'lık bir çok zayıf düzeyde bir etki büyüklügü tespit edilmiştir. Ancak bu etki büyüklüğünün de istatisksel olarak anlamlı olmadığı görülmüştür.

Meta-analiz sonuçları bir bütün olarak değerlendirildiğinde öğretmenlerin okul müdürlerinin yenilik yönetimi yeterliklerine yönelik algılarının cinsiyet açısından anlamlı bir farka neden olmadığı anlaşılmaktadır. Başka bir ifadeyle öğretmenlerin okul müdürlerinin yenilik yönetimi yeterliklerine iliş- 
kin algıları kadın veya erkek olmalarına bağlı olarak değişmemektedir. Anacak alanyazın incelendiğinde araştırmaların bazılarında öğretmenlerin cinsiyetleri ile okul müdürlerinin yenilik yeterliklerine ilişkin algıları arasında anlamlı bir ilişki varken (Argon ve Özçelik, 2007; Bayrakçı ve Eraslan, 2014; Erslan, 2014), bazılarında ise anlamlı bir ilişkinin olmadığı belirlenmiştir (Aydoğar, 2018; Dönmez, 2018; Eroğlu Bozkurt, 2019; Göl, 2012; Görgel, 2018; Kurt, 2016; Ömür, 2014; Öztürk, 2017; Selçuk, 2018; Şahin, 2018). Araştırmalarda öğretmenlerin okul müdürlerinin yenilik yönetimi yeterliklerine yönelik algılarının cinsiyet değişkeni bağlamında değişiklik gösterip göstermemesinin temel nedenlerinden birinin araştırmaların uygulandığı öğretim kademelerinin veya örneklem gruplarının özellikleriyle ilgili olduğu tahmin edilmektedir. Ayrıca gün geçtikçe yenilik yönetimine duyulan gereksinim ve okul müdürlerinin bu gereksinimlere göre kendilerini geliştirmek istemeleri yönündeki çabalarının da okul müdürlerinin yenilik yönetimi yeterlikleriyle ilgili öğretmen algılarının benzer olmasını sağlamış olabilir.

Araştırmada yer alan çalışmaların özellikle 2012-2017 ve 2018-2019 yılları arasında görece fazla olması, çalışma yılının moderatör değişken olarak ele alınmasını gerekli kılmıştır. Bu kapsamda çalışma yılına göre cinsiyet değişkeninde bir farklılık olup olmadığını belirlemek için moderatör analiz yapılmıştır. Ancak moderatör analiz sonuçlarında da her ne kadar 2018-2019 yıllarında yapılan çalışmların görece etki büyüklüğü daha yüksek olsa da bu etkinin istatiksel olarak anlamlı olmadığı tespit edilmiştir. Bu nedenle okul müdürlerinin yenilik yönetimi yeterliklerine yönelik algılarda cinsiyet bağlamında yıllara göre de farklılık olmadığı ortaya çımıştır.

Mevcut araştırmanın sonuçları okul müdürlerinin bilindik ve geleneksel yönetsel rolleri sergilemeye devam ettiklerine işaret etmektedir. Oysaki gelişen ve değişen bir dünyada yenilik yönetimi yeterliklerinin de değişnmesi veya gelişmesi gerektiği iddia edilebilir. Türkiye' de okul müdürlerinin atama usulüyle görev yapmaları, Türk eğitim sistemin bürokratik veya merkeziyetçi bir yapıya sahip olması eğitim örgütleri yöneticilerini yenilik ve değişim konusunda sınırlandırmış olabilir. Bununla birlikte Mulford'a (2003) göre okul müdürleriyle ilgili beklentiler paradigmatik dönüşümün bir sonucu olarak görülmekte ve söz konusu paradigmatik dönüşüm yeniliğin ve değişimin doğal bir sonucu olarak ortaya çıkmaktadır. Dolayısıyla değişim ve yenilik süreciyle birlikte okul müdürleri daha reformist ve daha girişimci olmak zorundadır (Erçetin, 2000; Foster, 2007). Bu nedenle okul müdürlerinin görev 
yaptıkları okullarda yenilikçi bir kültür oluşturmaları ve yenilik yönetimi yeterliklerini değişen koşullara göre güncel tutmaları gerekmektedir.

Araştırma sonuçlarından hareketle uygulayıcılara ve araştırmacılara aşağıdaki öenerilerde bulunulabilir;

- Okul müdürlerinin yenilik yönetimi yeterliklerini öğretmenlerin cinsiyetlerine göre incelenmesinin çok da anlamlı olmadığı söylenebilir. $\mathrm{Bu}$ bağlamda okul müdürlerinin yenilik yönetimi yeterliklerinin başka değişkenlerce incelenmesi (öğrenim durumu, öğretim kademesi, beşeri ve entelektüel sermaye v.b) yararlı olabilir.

- Araştırma uluslararası alanda yapılmış benzer diğer çalışmalarla tekrarlanabilir. Böylece okul müdürlerinin yenilik yönetimi yeterliklerine ilişkin daha doğru ve daha güvenilir karşılaştırmalı sonuçlar elde edilebilir.

- Okul müdürlerinin yenilik yönetimi yeterlikleri ile örgütsel çıktılar arasındaki ilişkiyi konu edinen meta-analiz çalışmaları yapılabilir. 


\title{
EXTENDED ABSTRACT
}

\section{Innovation Management of School Principals Qualifying Examination by Gender: A Meta-Analysis Study}

\author{
Müzeyyen Petek Dinçman \\ Hacettepe University
}

It can be stated that educational organizations at the macro level and schools at the micro level are among the organizations that need to operate innovations and innovation management processes in a much more advanced attitude. When national and international literature is analysed, it can be observed that a significant increase in the number of researches related to innovation management in schools in recent years can be seen. (Ağaoğlu, Altınkurt, Yılmaz and Karaköse, 2012; Akomolafe, 2011; Argon, İsmetoğlu and İşeri, 2014; Aydoğar, 2018; Bayrakçı and Eraslan, 2014; Boydak Ozan and Karabatak, 2013; Bülbül, 2012b; Damanpour and Schneider, 2006; Demiraçan, 2019; Dönmez, 2018; Göl, 2012; Greany, 2018; Eraslan, 2014; Eroğlu Bozkurt, 2019; Esen, 2016; Göl ve Bülbül, 2012; Görgel, 2018; Jolles, McBeath, Carnochan and Austin, 2016; Judd, 2017; Karaca, 2019; Top, 2011; Karataş, Gök and Özçetin, 2015; Koch, Binnewies and Dormann, 2015; Kurt, 2016; Min, Ling and Piew, 2016; Mürtezaoğlu, 2015; Orapeleng, 2017; Ömür, 2014; Öztürk, 2017; Park, 2012; Pihie, Asimiran and Bagheri, 2014; Selçuk, 2018; Şahin, 2018; Watt, 2002; Yaman, 2018). Some of these researches mentioned have been carried out at the national level, in accordance with the perceptions of teachers, so as to determine the innovation management competencies of school principals according to various personal (demographic) variables. (Aydoğar, 2018; Eraslan, 2014; Eroğlu Bozkurt, 2019; Dönmez, 2018; Göl, 2012; Görgel, 2018; Kurt, 2016; Ömür, 2014; Öztürk, 2017; Selçuk, 2018; Şahin, 2018).

Conversely, in other studies, there was a significant relationship between teachers 'gender and perceptions of school principals' innovation competencies (Argon and Özçelik, 2007; Bayrakçı and Eraslan, 2014; Erslan, 2014), while others did not show similar results (Aydoğar, 2018; Dönmez, 2018; Eroğlu Bozkurt, 2019; Göl, 2012; Görgel, 2018; Kurt, 2016; Ömür, 2014; Öztürk, 2017; Selçuk, 2018; Şahin, 2018). 
As can be observed, when looking at literature on the perceptions of teachers at the national level, it can be seen that in studies in which the school principals' innovation management competencies were examined there were different results in terms of gender variables. Because of this, the synthesis of school principals' innovation management competencies to the genders of the teachers by the use of meta-analysis will contribute to achieving clearer and more accurate results. With this in regard, the main purpose of bringing together the results of research examining the efficacy of innovation management in Turkey, with the school principals' views on teacher gender studies with the use of meta-analysis method is to reveal more comprehensive results of the studies carried out.

The research was done with the use of meta-analysis method, which is accepted as one of the pre-eminent literature scanning methods. Within the scope of the study, research which addressed the innovation management competencies of school principals according to the gender of the teachers were examined. Academic databases such as "Higher Education Council National Thesis Center, ULAKBİM National Database, Google Academy, EBSCOhost, Science Direct, ASOS, Scopus" were used to determine the studies to be included in the research. Scans in academic databases were carried out between 1 May 2020 and 10 May 2020 with the words "innovation, innovation, management, innovation management competencies, innovation, gender, innovation, innovation management, innovation management competencies, sex, gender" and advanced search features in databases. According to the specified criteria determined in the study, it was established that it was appropriate to include 11 studies in meta-analysis. The studies included in the research are indicated with an asterisk $\left(^{*}\right)$ in the bibliography. Validity and reliability of all studies included in the study were checked one by one. The coding process of the research was carried out with comprehensive and thorough means. Accordingly, the data coded within the scope of the research was re-coded by another independent researcher. The Cohen Kappa coefficient was calculated for the compatibility between the two encoders. The Cohen Kappa coefficient was found to be $\kappa=.94$.

The analyses related to the research were carried out with the Comprehensive Meta-Analysis 2.00 (CMA 2.00) package program. Standardized Means Difference (SOF) method, also known as Cohen d, was used for the effect sizes of the studies. Value between $00-.10$ is a very weak effect size, $.10-.30$ 
value is a weak level effect size, .30 - .50 value is a medium level effect size, $.50-.80$ value is a strong level effect size and .80 ' values which are greater than are considered as a very strong effect size (Cohen, Manion and Morrison, 2007). In this framework, the sample size (male and female) of each study and the mean value of the belonging, standard deviation, $t$ and $p$ values were examined. In the study, women were coded as 1 and men were coded as 0 .

In the study, positive effect size means that women and negative effect size means that men have more positive perceptions about innovation management competences. Also, in order to decide which model to use in the research, the results of homogeneity test were examined. $Q$ and $p$ values were taken as criteria for homogeneity test. In the relationship between gender and innovation management competence perception, the years of studies are defined as the moderator variable (2012-2017 and 2018-2019). Funnel Plot, Egger test, Begg and Mazumdar rank correlation" values were examined to determine whether there were any publication bias' of the study. In the research, statistical significance was interpreted at the level of $\mathrm{p}=.05$. The funnel scatter plot findings indicate that the research had no publication bias'. As a result of the Egger test, $\mathrm{p}$ value is higher than .79 and .05 , Tagg value is $0.1818, \mathrm{Z}$ value is .07785 and $p>.05(p=.93)$ in the Begg and Mazumdar Correlation test (Card, 2012). This confirms the findings that there were no observable bias in the study. As a result of the heterogeneity test, it was determined that $Q=$ $8.951, \mathrm{df}=10, \mathrm{p}=.537$. Accordingly, it was understood that the study was homogeneous since the $p$ value was greater than .05 and the $Q$ value was less than 18.307 in the $x 2$ table. Thus, the effect size calculated according to the fixed effects model has been taken into consideration.

For all 11 studies examining the effect of gender on the perception of innovation management, the effect size according to the fixed effects model was found in favour of women with a value of .006. However, it can be seen that this effect is not statistically significant. Therefore, it can be said that gender does not have an impact on the perception of innovation management. According to the publication year of the studies, the effect size in terms of gender was between -0.029 for the years of 2012 to 2017; It has been calculated as 0.030 for the years of 2018 to 2019. In terms of the moderator of the study year, the variance value between the studies was not statistically significant $(\mathrm{Qb}=$ $8.889, \mathrm{p}>$.05). Accordingly, it was determined that the year of study did not significantly change the effect size in terms of gender. 
Based on the findings gathered from the research, the following suggestions can be made to research specialists and researchers;

- It can be said that it is not very meaningful to examine the school principals' innovation management competencies according to the gender of the teachers. In this context, it may be useful to examine school administrators' innovation management competencies by other variables (educational level, teaching level, human and intellectual capital, etc.).

- The research can be repeated with other similar international studies. Thus, more accurate and more reliable comparative results can be obtained regarding school administrators' innovation management competencies.

- Meta-analysis studies can be conducted on the relationship between school principals' innovation management competencies and organizational outputs.

\section{Kaynakça / References}

Adair, J. (2015). Yenilikçi liderlik (Çev.: S. Uyan). İstanbul: Babıali Kültür Yayınclığı. Ağaoğlu, E., Altınkurt, Y., Yllmaz, K., ve Karaköse, T. (2012). Okul yöneticilerinin yeterliklerine ilişkin okul yöneticilerinin ve öğretmenlerin görüşleri: Kütahya ili. Eğitim ve Bilim Dergisi, 37(164), 159-175.

Akomolafe, C. O. (2011). Managing innovations in educational systems in Nigeria: A focus on creating and sustenance of culture of innovation. Journal of Emerging Trends In Educational Research and Policy Studies, 2(1), 47-52.

Argon, T., İsmetoğlu, M., ve İşeri, B. (2014). Okul yöneticilerinin değerlere göre yönetim ile yenilik yönetimlerine yönelik öğretmen görüşleri. Eğitim ve Öğretim Araştırmalarn Dergisi, 3(4), 111-119.

Argon, T., ve Özçelik, N. (2007). İlköğretim okul yöneticilerinin değişimi yönetme yeterlikleri. Mehmet Akif Üniversitesi Ĕ̆itim Fakültesi Dergisi, 17, 77-94.

Aydoğar, N. (2018). Okul yöneticilerinin yenilik yönetimi becerilerinin öğretmen görüşlerine göre incelenmesi:Kahramanmaraş il merkezi özel ve devlet okullarn örneği. Yayımlanmamış yüksek lisans tezi, Sütçü İmam Üniversitesi, Sosyal Bilimler Enstitüsü, Kahramanmaraş.

Bayrakcı, M., ve Eraslan, F. (2014). Ortaöğretim okul yöneticilerinin inovasyon yeterlilikleri. Sakarya Üniversitesi Ĕ̆itim Fakültesi Dergisi, 28, 100-141. 
Beycioğlu, K., ve Aslan, M. (2009). Okul gelişiminde temel dinamik olarak değişim ve yenileşme: okul yöneticileri ve öğretmen rolleri. Yüzüncü Yıl Üniversitesi Ĕ̆itim Fakültesi Dergisi, 6(2), 166-186.

Borenstein, M. Hedges, L. V., Higgins, J. P. T., ve Rothstein, H. R. (2013). Meta-analize giriş. (Çev.: S. Dinçer). Ankara: Yayıncllık.

Boydak Ozan, M., ve Karabatak, S. (2013). Ortaöğretim okul yöneticilerinin yenilik yönetimine yaklaşımlanı ve karşılaştıkları sorunlar. International Journal of Educational Science, 5(1), 258-273.

Bursalığlu, Z. (2012). Okul yönetiminde yeni yapı ve davranış. Ankara: Pegem Akademi Yayıncilik.

Bülbül, T. (2012a). Okullarda yenilik yönetimi ölçeği'nin geliştirilmesi: geçerlik ve güvenilirlik çalışması. Kuram ve Uygulamada Ĕ̆itim Bilimleri, 12(1), 157-175.

Bülbül, T. (2012b). Okul yöneticilerinin yenilik yonetimine iliskin yeterlik inançlari. [School administrators' efficacy beliefs towards innovation management]. Trakya Universitesi Sosyal Bilimler Dergisi, 14(1), 45-68.

Bülbül, T. (2013). Yenilik yönetimi. H. B. Memduhoğlu ve K. Yılmaz (Edt.). Yönetimde yeni yaklaşımlar içinde (s.31-51). Ankara: Pegem Akademi Yayınclık.

Card, N. A. (2012). Applied meta-analysis for social science research. New York: The Guilford Press

Cohen, L., Manion, L. ve Morrison, K. (2007). Research method in education (6th edition). New York: Taylor \& Francis e-Library.

Cooper, H., Hedges, L. V., ve Valentine, J. C. (2009). The handbook of research synthesis and meta-analysis (2nd edition). New York: Russell Sage Publication.

Cumming, G. (2012). Understanding the new statistics: effect sizes, confidence intervals, and meta-analysis. New York: Routledge.

Damanpour, F., ve Schneider, M. (2006). Phases of the adoption of innovation in organizations: Effects of environment, organization and top managers. British Journal of Management,17, 215-236.

Demiraçan, A. (2019). Okul yöneticilerinin teknoloji liderliği stratejileri ile yenilik yönetimi yeterlik inançlan arasındaki ilişkinin incelenmesi. Yayımlanmamış yüksek lisans tezi, Trakya Üniversitesi, Sosyal Bilimler Enstitüsü, Edirne.

Demirci, A. E. (2013). Yenilik yönetimi. S. Sözen (Edt.). Yönetimde bilimi-II içinde (s. 142159). Ankara: Saray Matbaacilik.

Dinçer, S. (2014). Eğitim bilimlerinde uygulamalı meta-analiz. Ankara: Pegem Akademi Yayıncilık. 
Dönmez, E. (2018). Okul müdürlerinin örgütsel yenilik yönetimi dauranış düzeyi ile öğretmenlerin örgütsel bağhllk düzeyleri arasındaki ilişki. Yayımlanmamış yüksek lisans tezi, Muğla Sıtkı Koçman Üniversitesi, Eğitim Bilimleri Enstitüsü, Muğla.

Drucker, P. F. (2003). Yenilikçilik disiplini içinde yenilik. (Çev.: A. Kardan). İstanbul: Mess Yayıncilik.

Durna, U. (2002). Yenilik yönetimi. Ankara: Nobel Yayınları.

Duval, S., ve Tweedie, R. (2000). Trim and fill: A simple funnel-plot-based method of testing and adjusting for publication bias in meta-analysis. Biometrics, 56, 455463.

Eraslan, F. (2014). Ortaöğretim okul yöneticilerinin inovasyon yeterlilikleri. Yayımlanmamış yüksek lisans tezi. Sakarya Üniversitesi, Eğitim Bilimleri Enstitüsü. Sakarya.

Erçetin, S. S. S. (2000). Lider sarmalinda vizyon. Ankara: Nobel Yayın Dağtım.

Eroğlu Bozkurt, B. (2019). Mesleki ve teknik anadolu lisesi müdürlerinin inovasyon yeterlilikleri ile okullarn yenilikçilik düzeyleri arasındaki ilişki. Yayımlanmamış yüksek lisans tezi, Anadolu Üniversitesi, Eğitim Bilimleri Enstitüsü, Eskişehir.

Esen, F. (2016). Okul öncesi eğitim öğretmenlerinin algllarnna göre okul müdürlerinin liderlik stilleri ile yenilik yönetimi arasındaki ilişki. Yayımlanmamış yüksek lisans tezi, İstanbul Aydın ve Yıldız Teknik Üniversitesi, Sosyal Bilimler Enstitüsü, İstanbul.

European Commission (2004). Innovation management and the knowledge-driven economy. Lüksemburg.

Foster, L. (2007). Changing secondary school leaders' role in public education, changing role of the middle level and high school leader: learning from the past-preparing for the future. National Association of Secondary School Principals, 1-4.

Fullan, M. (2007). The new meaning of educational change fourth edition. New York ve Londra: Teachers College Press.

*Göl, E. (2012). İlköğretim okulu yöneticilerinin yenilik yönetimi yeterliklerine ilişkin öğretmen algıları Kırklareli ili örneği. Yayımlanmamış yüksek lisans tezi. Trakya Üniversitesi, Sosyal Bilimler Enstitüsü, Edirne.

Göl, E., ve Bülbül, T. (2012). Illköğretim okulu yöneticilerinin yenilik yönetimi yeterliklerine ilişkin öğretmen algiları. Mersin Üniversitesi Ë̆itim Fakültesi Dergisi, 8(2), 97-109.

Görgel, H. M. (2018). Okul yöneticilerinin yenilik yönetimi yeterliklerine ilişkin öğretmen ve okul yöneticisi algılarınin incelenmesi. Yayımlanmamış yüksek lisans tezi. Sütçü İmam Üniversitesi, Sosyal Bilimler Enstitüsü, Kahramanmaraş. 
Greany, T. (2018). Innovation is possible, it's just not easy: Improvement, innovation and legitimacy in England's autonomous and accountable school system. Educational Management Administration \& Leadership, 46(1), 65-83.

Günbayı, İ. (2016). Liderlik ve toplumsal değişme. N. Güçlü ve S. Koşar (Edt.). eğitim yönetiminde liderlik teori, araştırma ve uygulama içinde (s. 245-282). Ankara: Pegem Akademi Yayınclik.

Hadfield, G. H. (2008). Legal barriers to innovation: The growing economic cost of Professional control over corporate legal markets. Stanford Law Review, 60(6), 16891732.

Higgins, J. P., Thompson, S. G., Deeks, J. J., ve Altman, D. G. (2003). Measuring inconsistency in meta-analyses. Bmj, 327(7414), 557-560.

Jolles, M. P., McBeath, B., Carnochan, S., ve Austin, M. J. (2016) Factors associated with managerial innovation in public human service organizations, Human Service Organizations: Management, Leadership \& Governance, 40(4), 421-434.

Judd, J. (2017). Exploring transformational leadership: How heads of school foster and support innovation in schools (Order No. 10262340). Available from ProQuest Dissertations \& Theses Global.(1892454603).

Karaca, B. (2019). Okul yöneticilerinden ilkokul müdürlerinin yenilik yönetimi yeterliliklerine ilişkin öğretmen algzlarn: İstanbul ili Beykoz ilçesi örneği. Yayımlanmamış yüksek lisans tezi, Beykent Üniversitesi, Sosyal Bilimler Enstitüsü, İstanbul.

Karataş, S., Gök, R., ve Özçetin, S. (2015). Okul yöneticilerinin yenilik yönetimi yeterliklerine ilişkin öğretmen algiları. Mehmet AkifErsoy Üniversitesi Ë̆itim Fakültesi Dergisi, 1(33), 167-185.

Koch A. R, Binnewies C., ve Dormann, C. (2015). Motivating innovation in schools: School principals' work engagement as a motivator for schools' innovation. European Journal of Work and Organizational Psychology, 24(4), 505-517.

Kuczmarski, T. (1996). Innovation leadership strategies for the competitive edge. USA: NTC Business Boks.

Kurt, A. (2016). Yönetici inovasyon yeterliliği ve okul kültürü ilişkisi:Bolu ili örneği. Yayımlanmamış yüksek lisans tezi. Abant İzzet Baysal Üniversitesi, Eğitim Bilimleri Enstitüsü, Bolu.

Mulford, B. (2003). School leaders: changing roles and impact on teacher and school effectiveness. $O E C D, 1-65$.

Mürtezaoğlu, S. (2015). Pozitif-negatif duygularm, otomatik düşüncelerin ve bazı kişisel değişkenlerin okul yöneticilerinin yenilik yönetimi yeterlik inanç düzeyleri üzerindeki etkisi. Yayımlanmamış yüksek lisans tezi, Aydın Üniversitesi, Sosyal Bilimler Enstitüsü, İstanbul. 
Min, W. Z., Ling, K. C., ve Piew, T. H. (2016). The effects of technological innovation, organizational innovation and absorptive capacity on product innovation: a structural equation modeling approach. Asian Social Science, 12(1), 199-221.

Naktiyok, A. (2007). Yenilik yönelimi ve örgütsel faktörler. İktisadi ve İdari Bilimler Dergisi, 21(2), 211-230.

Orapeleng, S. R. (2017) Innovative leadership in managing conflict at selected senior secondary schools in Botswana. Unpublished master thesis. Pretoria: University of South Africa.

Öğüt, A., Aygen, S., ve Demirel, M. (2007). Personel güçlendirme inovasyonu hızlandırır mı? antalya ili beş yıldızlı konaklama işletmelerine yönelik görgül bir araştırma. Selçuk Üniversitesi İ.I.BF Dergisi Yerel Ekonomiler Özel Sayısı, 163172.

Ömür, Y. E. (2014). Lise yöneticilerinin yenilik yönetimi becerileri ile okullardaki örgütsel öğrenme mekanizmalarna yönelik görüşleri. Yayımlanmamış yüksek lisans tezi, Abant İzzet Baysal Üniversitesi, Eğitim Bilimleri Enstitüsü, Bolu.

Özevren, M. (2000). Toplam kalite yönetimi. İstanbul: Alfa Basım Yayım.

Öztürk, M. (2017). İlkokul müdürlerinin yenilik yönetimi yeterliklerine ilişkin öğretmen algları: istanbul ili avclar ilçesi örneği. Yayımlanmamış yüksek lisans tezi, İstanbul Aydın ve Ylldız Teknik Üniversitesi, Sosyal Bilimler Enstitüsü, İstanbul.

Park, J. H. (2012). The effects of principal's leadership style on support for innovation: evidence from Korean vocational high school change. Asia Pacific Education Review March, 13(1), 89-102.

Pervaiz, K. A. (1998). Culture and climate for innovation. European Journal of Innovation Management, 1(1), 30-43.

Pihie Z., Asimiran. S., ve Bagheri, A. (2014). Entrepreneurial leadership practices and school innovativeness. SA Journal of Education, 34(1), 1-11.

Rammel, C. (2003). Sustainable development and innovations: lessons from the red queen. International Journal of Sustainable Development, 6, 395-416.

Rothstein, H. R., Sutton, A.J. ve Borenstein, M. (2005). Publication bias in meta-analysis. Publication bias in meta-analysis: prevention, assessment and adjustments. NJ: Wiley \& Sons.

Selçuk, S. (2018). Özel ortaöğretim kurumlarnda yöneticilerin inovasyon yeterlilikleri ile örgütsel imaj algıst ilişkisi. Yayımlanmamış yüksek lisans tezi, Hacettepe Üniversitesi, Eğitim Bilimleri Enstitüsü, Ankara. 
Sönmez, A. N., ve Çekmecelioğlu, H. G. (2016). Yenilik yönetimi ve yenilik yönetimini etkileyen faktörlerin yenilik performansı açısından incelenmesi: yenilik desteği alan işletmeler üzerinde bir araştırma. Eurasian Academy of Sciences Eurasian Business \& Economics Journal, 1, 419-429.

Şahin, K. (2018). Ortä̈ğretim okul yöneticilerinin yenilik yönetimi yeterlikleri ile girişimcilik yeterlikleri arasındaki ilişki. Yayımlanmamış yüksek lisans tezi. 18 Mart Üniversitesi, Eğitim Bilimleri Enstitüsü, Çanakkale.

Top, M. Z. (2011). Ilköğretim okul yöneticilerinin yenilik yönetimine ilişkin tutumlarmin incelenmesi. Yayımlanmamış yüksek lisans tezi. Marmara Üniversitesi, Eğitim Bilimleri Enstitüsü, İstanbul.

Uzkurt, C. (2008). Yenilik yönetimi ve yenilikçi örgüt kültürü. İstanbul: Beta Yayınları.

Üstün, U., ve Erylmaz, A. (2014). Etkili araştırma sentezleri yapabilmek için bir araştırma yöntemi: meta-analiz. Eğitim ve Bilim, 39(174), 1-32.

Varış, F. (1982). Eğitimde yenileşme kavramı. Ankara Üniversitesi Eğitim Bilimleri Fakültesi Dergisi, 15(1), 56-60.

Watt, D. (2002). How innovation occurs in high schools within the network of innovative schools: The four pillars of innovation research project. The Conference Board of Canada. Retrieved April 12, $2020 \mathrm{http} / / / w w w . b i s h o p s . ~ k 12 . n f . ~ c a / p o s t e r /$ fourpillars.pdf

\section{Kaynakça Bilgisi / Citation Information}

Dinçman, M. P. (2020). Okul müdürlerinin yenilik yönetimi yeterliklerinin cinsiyete göre incelenmesi: Bir meta-analiz çalışması. OPUS-Uluslararası Toplum Araştırmaları Dergisi, 16(31), 4238-4264. DOI: 10.26466/opus.739482 